\title{
APONTAMENTOS SOBRE O ENSINO DE CIÊNCIAS NA EDUCAÇÃO INFANTIL
}

\author{
Appointments about the teaching of Science in early Childhood Education \\ Apuntes sobre la enseñanza de las Ciencias en la Educación Infantil
}

\author{
Renata Gonçalves Vieira ${ }^{1}$ \\ Ademir de Souza Pereira ${ }^{2}$ \\ Hiraldo Serra ${ }^{3}$
}

\begin{abstract}
Resumo
O ensino de ciências na educação da infância é de grande importância por trazer como premissa a ação ativa da criança e a valorização às iniciativas de investigação e construção do conhecimento em atividades desafiadoras. Esse estudo buscou investigar por meio de pesquisa bibliográfica, concepções e orientações para o ensino de ciências na educação infantil, de forma a favorecer a contextualização do trabalho didático-pedagógico e privilegiar o desenvolvimento de habilidades e competências no que concerne aos conteúdos dessa área do conhecimento. As concepções e orientações descritas nesse trabalho ressaltam que o ensino de ciências na educação infantil, pode representar momentos significativos para as crianças, principalmente quando elas têm uma participação ativa, despertando o interesse para a aprendizagem do conteúdo específico e contribuindo para desenvolvimento cognitivo.
\end{abstract}

PALAVRAS-CHAVE: Contextualização. Participação ativa. Criança. Investigação.

\begin{abstract}
The teaching of science in the education of children is of great importance in premise of child active action, appreciation of initiatives of research and knowledge building in challenging activities. This study aimed to investigate by means of literature, concepts and guidelines for teaching science in early childhood education, to favor the contextualization of teaching and pedagogical work and focus on the development of skills and competencies in relation to the contents of this area of knowledge. The concepts and guidelines described in this study emphasize the teaching of science in early childhood education, may represent very significant moments for children, especially when they have active participation, arousing interest for learning specific content and contributing to cognitive development.
\end{abstract}

KEYWORDS: Contextualization. Active participation. Child. Research.

\section{Resumen}

\footnotetext{
1 . Licenciada em Pedagogia pela Faculdade de Educação da Universidade Federal da Grande Dourados. Email: renata_g_v@hotmail.com

2. Doutorando pelo Programa de Pós-graduação em Educação para a Ciência UNESP/Bauru-SP. Docente da Faculdade de Ciências Exatas e Tecnologia da Universidade Federal da Grande Dourados. E-mail: ademirpereira@ufgd.edu.br.

${ }^{3}$ Docente da Faculdade de Educação da Universidade Federal da Grande Dourados - Dourados-MS, Brasil. E-mail: hiraldoserra@ufgd.edu.br.
} 
La enseñanza de las ciencias en la educación de la infancia es de gran importancia por traer como premisa la acción activa del niño y la valorización a las iniciativas de investigación y construcción del conocimiento en actividades desafiantes. Este estudio buscó investigar, por medio de investigación bibliográfica, concepciones y orientaciones para la enseñanza de ciencias en la educación infantil, de forma a favorecer la contextualización del trabajo didáctico-pedagógico y privilegiar el desarrollo de habilidades y competencias en lo que concierne a los contenidos de esa área del conocimiento. Las concepciones y orientaciones descritas en este trabajo resaltan que la enseñanza de las ciencias en la educación infantil puede representar momentos significativos para los niños, principalmente cuando tienen una participación activa, despertando el interés para el aprendizaje del contenido específico y contribuyendo al desarrollo cognitivo.

PALABRAS CLAVE: Contextualización. Participación activa. Infantil. Investigación.

\section{INTRODUÇÃO}

Atualmente, a defesa da necessidade do ensino de ciências na educação infantil encontra-se bastante presente, pois desde muito cedo as crianças se deparam com elementos da natureza e artefatos tecnológicos nas vivências de seu dia a dia, tornando-se imprescindível que se ofereça a elas subsídios para que possam melhor compreender a realidade que as cerca.

O estudo buscou investigar por meio de pesquisa bibliográfica, concepções e orientações para o ensino de ciências na educação infantil de forma a favorecer a contextualização do trabalho didático-pedagógico no sentido de privilegiar $\mathrm{o}$ desenvolvimento de habilidades e competências no que concerne aos conteúdos dessa área do conhecimento.

O ensino de ciências na educação infantil a partir do desenvolvimento de atividades diversificadas pode favorecer uma formação inicial de conceitos à criança, bem como, prepará-la para o estudo de conteúdos de maior complexidade em sua futura trajetória escolar, possibilitando-lhe uma melhor compreensão e construção dos conhecimentos científicos. Atividades teórico-práticas planejadas nesse contexto devem ser desafiadoras e ter como foco a ação da criança, sua participação ativa no processo ensino-aprendizagem e na aquisição de novos conhecimentos.

Nesta perspectiva, o ensino de Ciências necessita ser valorizado porque possibilita aos alunos compreender o dinamismo e a diversidade dos fenômenos naturais, incentivando-os a buscarem explicações lógicas e desenvolverem posturas críticas em contextos sociais. Assim, é necessário se reconhecer a importância do ensino de ciências naturais como fator de grande relevância da formação integral do educando e para o exercício pleno da cidadania.

A primeira parte do texto tem como foco o ensino inicial de ciências na qual ocorre a descrição das primeiras concepções de currículo para a educação infantil, além da perspectiva específica da área, destaca as representações que as crianças oferecem e que devem ser consideradas para que se atenda à grande diversidade de possibilidades de exploração do mundo por elas.

Na segunda parte do texto, a construção do conhecimento científico na educação infantil, encontra-se indicada a urgência de se considerar como de extrema importância as situações novas vivenciadas pelas crianças e experiências com pessoas e diferentes objetos. É defendida a concepção de que atividades em diversos espaços de aprendizagem 
possibilitam às crianças, a apreciação e consciência por diversos elementos, tanto do meio físico como do meio social, contribuindo para o aprimoramento e construção de novos conhecimentos.

Finalmente, na terceira parte do texto, a aprendizagem construtivista de ciências na educação infantil, acentua-se que a aprendizagem significativa ocorre nos momentos em que a criança é protagonista no processo ensino aprendizagem, participando ativamente nas diversas atividades desenvolvidas. A aprendizagem sensorial é ressaltada por que ocorre de forma intensa nas atividades práticas favorecendo o desenvolvimento de habilidades científicas como as de observação e investigação, promovendo a autonomia e propiciando diálogo, discussão e reflexão.

\section{O ensino inicial de Ciências}

Na educação infantil, primeiro nível da educação básica, já existe a necessidade de que ocorra o ensino levando-se em conta a integração de diversas áreas do conhecimento. Ensinar Ciências nesse nível de ensino significa respeitar essa premissa e levar em conta uma grande diversidade de possibilidades de exploração do mundo pelas crianças.

Segundo Rosa (2007), muitos dos temas enfocados no ensino de ciências são de interesse das crianças sobre os quais elas já se perguntam e constroem concepções e representações. No planejamento de atividades envolvendo conhecimentos dessa área, é possível oportunizar que as crianças interajam com diferentes materiais, que possam formular hipóteses e se expressar na busca por explicar novas ideias.

Segundo Trundle e Sackes (2008), as crianças pequenas estão ativamente envolvidas com o seu ambiente, dispostas a desenvolver compreensões fundamentais dos fenômenos que estão observando e experimentando. Uma postura desejável no ensino de Ciências é a de se criar momentos nos quais as crianças, no contato com diferentes materiais, possam ampliar sua curiosidade e interesse na exploração de seus atributos.

A construção do conhecimento, bem como, a de regras e valores ocorre por meio de sua ação sobre o meio físico e social, onde cabe oportunizar situações interativas em que a criança possa fazer escolhas, expressar pontos de vista e tomar decisões. Os processos pedagógicos não devem estar somente restritos à realização de atividades, mas também na reflexão sobre seu sentido no cotidiano da criança, procedimentos que irão contribuir muito para o desenvolvimento de sua autonomia (TU; HSIAO, 2008).

Os conhecimentos científicos básicos e as ferramentas para o entendimento do processo científico se iniciam nos primeiros anos da infância, com a sofisticação do desenvolvimento de competências das crianças em diferentes idades (PIAGET; INHELDER, 2000).

No processo de ensino e aprendizagem se faz necessário a investigação das concepções e representações que as crianças já possuem sobre o mundo que as cerca, conhecimentos prévios e concepções alternativas advindas do senso comum, devendo ser consideradas na construção do conhecimento científico. Atividades práticas ou experimentais que privilegiem a observação e exploração dos sentidos podem desempenhar um papel importante nesse contexto, estimulando o interesse das crianças pela investigação (TU; HSIAO, 2008). 
O estudo das ciências tem sido uma parte importante dos currículos elementares e de primeira infância desde o início do século XX. Um dos precursores dessa ideia foi o filósofo e psicólogo norte-americano John Dewey que defendia sua inclusão na educação de crianças pequenas (SPODEK; SARACHO, 1998). Segundo os autores, no início do referido século, algumas escolas cultivavam a prática de levar as crianças para o campo para que pudessem observar a natureza e os elementos nela existentes.

O pedagogo alemão Friedrich Wilhelm Froebel (1782-1852), denominado "criador do jardim de infância", definiu o ensino de ciências como uma filosofia de instrução. Ele acreditava que os alunos mais novos deviam ser participantes ativos na aprendizagem e destacava a importância de se respeitar as crianças, pois elas gostam de aprender (EDIGER, 1989). Segundo o autor, o jardim de infância de Froebel incluía o estudo da natureza, citando a necessidade de que os professores mantivessem um jardim para que as crianças pudessem cultivar e também observar pequenos animais.

Segundo Spodek e Saracho (1998), os professores tinham a prática de trazer pedras e folhas para a sala de aula e colocavam-nas em mesas para que as crianças as pudessem observar, liam histórias sobre a natureza e mostravam figuras para enriquecer a aprendizagem. Segundo os autores, a finalidade destas atividades era desenvolver nas crianças o respeito pelo mundo natural e a apreciação de suas maravilhas.

Após a metade do século XX, o estudo de ciências começou a substituir o estudo da natureza na primeira infância e na educação primária. A inclusão dos jardins de infância nas escolas primárias pode ter significado um impulso para a expansão de seu currículo, muito além das três habilidades básicas (leitura, escrita e matemática). A educação em Ciências, em sua nova forma, utilizou-se menos de apreciação e mais de entendimento dos conceitos e dos métodos científicos, mesmo que em um nível bastante simples (JENESS, 1987).

Elementos do estudo da natureza são encontrados ainda hoje em turmas de primeira infância, quando os professores expõem materiais e leem história de natureza antropomórfica (SPODEK; SARACHO, 1998). Segundo os autores, embora a apreciação da natureza e a observação dos fenômenos naturais sejam boas atividades, os professores devem desenvolver outras de forma diversificada, para melhorar as habilidades de observação das crianças, ensinar-lhes que a apreciação da natureza requer um entendimento de como preservá-la e dos efeitos que a tecnologia pode ter sobre ela.

Segundo Howe (1993), pouco conteúdo de ciências era ensinado nas escolas até os anos de 1960, no entanto, foi um período em que novas "matérias" foram desenvolvidas para as crianças pequenas, como parte de uma vasta transformação que visava reformar o currículo escolar. Um dos estímulos a essa transformação foi a teoria defendida por Jerome Bruner (1960, p. 33) de que "qualquer matéria pode ser ensinada de alguma forma intelectualmente honesta para qualquer criança em qualquer estágio de desenvolvimento". Nessa época, ocorreu o início de um período intenso de desenvolvimento dos currículos, dos quais a maior parte era voltada para a criança em idade de jardim de infância.

Segundo Scriptori (2005), os escritos de John Dewey tiveram grande influência nos modelos curriculares para a primeira infância, que passaram a ressaltar a importância das experiências concretas, pessoais e significativas, na compreensão do mundo. $\mathrm{O}$ aprendizado de ciências no nível de pré-jardim de infância passou a ser visto como legítimo, devido ao interesse naquele momento na teoria piagetiana e a ideia de que as crianças pequenas eram capazes de adquirir conhecimento científico de modo intuitivo e por meio de experiências reais (KITCHER, 1988). 


\section{A construção do conhecimento científico na educação infantil}

A curiosidade e a observação são características presentes nas crianças desde muito pequenas e é por meio dessas características e das perguntas que fazem aos adultos, que as crianças buscam entender e compreender o mundo que as cerca, tanto o físico como o social. Atualmente elas convivem desde muito cedo com os chamados "produtos da ciência", um mundo repleto de tecnologia, no qual elas têm a oportunidade de manipular objetos e experimentar ações na busca por explicações sobre como os mesmos funcionam (TU; HSIAO, 2008).

Croft (2000) defende que as crianças aprendem melhor por meio de experiências diretas. Segundo o autor, as crianças têm curiosidade inata, pois ao perceberem que podem descobrir coisas por si mesmas, seu primeiro encontro com a ciência já ocorreu. As crianças buscam constantemente entender o "como" e o "porquê" das coisas e dos fenômenos da natureza e da sociedade em que vivem.

Experiências em ciências oferecem oportunidades para que as crianças desenvolvam apreciação e consciência do mundo em torno delas e possam desenvolver habilidades de investigação científica (CHALUFOUR; WORTH, 2003). Segundo os autores, a maneira como a criança tenta explicar os elementos do mundo que acerca, por meio de suas inquietações e interpretações, pode levá-la a se confrontar com explicações historicamente elaboradas sobre fenômenos naturais e de fatos sociais.

Lind (2000) acredita que as experiências vivenciadas pelas crianças necessitam ser compreendidas como lições, atividades estruturadas de aprendizagem, iniciadas pelos adultos, para que elas se sintam verdadeiramente envolvidas. O autor ainda salienta que as crianças podem aprender por meio de "experiências naturalistas", que ele define como aquelas iniciadas em conjunto com outras crianças, aquelas que a criança realiza de forma espontânea no seu dia a dia.

Desta forma, na interação com situações novas e com outras pessoas, as crianças têm a oportunidade de ir se apropriando do conhecimento científico de forma gradativa por meio de hipóteses que ela mesma é capaz de construir. Tu e Hsiao (2008) enfatizam a importância da Ciência na vida das crianças e acreditam que os primeiros anos são excelentes para a aprendizagem ativa e que a ciência pode desempenhar um papel importante no desenvolvimento delas.

Os espaços nos quais a criança convive socialmente com adultos e com outras crianças podem criar oportunidades para que ela construa e descubra diferentes aspectos da natureza e da cultura. Neste contexto, os Referenciais Curriculares Nacionais para Educação Infantil vêm afirmar que,

O mundo onde as crianças vivem se constitui em um conjunto de fenômenos naturais e sociais indissociáveis diante do qual elas se mostram curiosas e investigativas. Desde muito pequenas, pela interação com o meio natural e social no qual vivem, as crianças aprendem sobre o mundo, fazendo perguntas e procurando respostas às suas indagações e questões. Como integrantes de grupos socioculturais singulares, vivenciam experiências e interagem num contexto de conceitos, valores, idéias, objetos e representações sobre os mais diversos temas a que têm acesso na vida cotidiana, construindo um conjunto de conhecimentos sobre o mundo que as cerca (BRASIL, 1998, p. 163). 
Segundo Luria (1985), nos primeiros anos de desenvolvimento, antes de atingir a idade escolar, a criança já aprendeu e assimilou certo número de técnicas que preparam o caminho para a alfabetização. $\mathrm{O}$ autor afirma que as crianças adquirem conhecimentos prévios antes mesmo de adentrar a escola e estes devem ser levados em consideração. $\mathrm{O}$ autor afirma ainda, que esses conhecimentos espontâneos adquiridos pelas crianças no seu mundo real é o que torna possível a concretização do processo ensino-aprendizagem, já a partir da educação infantil.

Carvalho (2003) destaca as contribuições de dois estudiosos Jean Piaget e Lev Semynovich Vygotsky, quanto às concepções prévias que as crianças possuem mesmo antes de chegar ao ambiente escolar. Segundo a autora, ambos defendiam que não considerar as concepções prévias das crianças sobre conceitos e fenômenos, prejudicaria o processo ensino-aprendizagem e o processo de construção do conhecimento, pois a relação existente entre os conhecimentos espontâneos e científicos deve ser considerada.

Desta forma, os professores devem ter consciência de suas responsabilidades pedagógicas, pois podem desempenhar um papel de fundamental importância no apoio para expansão da aprendizagem científica das crianças (ELIASON; JENKINS, 2003). Desta forma, por meio de uma atitude de socialização com as crianças, incentivando-as nas atividades infantis e fazendo perguntas para promover o pensamento crítico, o professor passa a ter um papel crucial para a expansão da aprendizagem em ciências (RILEY; ROACH, 2006).

Segundo Bizzo (2002), as aulas de ciências geralmente são cercadas de muita expectativa e interesse por parte dos alunos, num momento em que a motivação flui naturalmente, levando-se em conta o estímulo para enfrentar desafios e investigar diversos aspectos da natureza na qual eles estão inseridos. A partir do momento que o professor prepara um ambiente propício para atividades de ciências é criada uma atmosfera favorável para as explorações das crianças, em muitos sentidos, possibilitando o surgimento de perguntas, muitas ideias e desafios (WORTH; GROLLMAN, 2003).

Vygotsky (2005) acreditava que as crianças são ajudadas e influenciadas pelas pessoas ao seu redor na construção do conhecimento e ele também acreditava que os professores devem ter um papel ativo no trabalho com as crianças para ajudá-las a alcançar seu potencial de aprendizagem. Segundo o autor, o elo central do processo de aprendizagem é a formação de conceitos. O autor compara e inter-relaciona duas categorias de conceitos: conceitos espontâneos, construídos cotidianamente pela ação direta das crianças frente à realidade experimentada e observada por elas; e os conceitos científicos, construídos em situações formais de ensino-aprendizagem.

Ainda segundo Vygotsky (2005), os conceitos espontâneos percorrem muitos caminhos até a criança ser capaz de defini-los verbalmente, já os conceitos científicos, que partem de uma definição, precisam aliar a formulação científica à experiência das crianças. De acordo com Hill, Stremmel e Fu (2005), o professor deve promover a articulação entre os conceitos espontâneos, trazidos pela criança e os científicos, veiculados na escola, de modo que os conceitos espontâneos possam inserir-se em uma visão mais abrangente do real e os conceitos científicos tornem-se mais concretos, apoiando-se nos conceitos espontâneos gerados na própria vivência da criança.

Carvalho (2003) destaca que,

"[...] a construção do conhecimento na fase inicial da vida do ser humano, não é algo para se deixar de lado. Há todo um conhecimento por trás de cada brincadeira e cada pergunta feita pela criança. A professora tem o 
papel de desvendá-lo, possibilitando, ao grupo de crianças, vivências que explorem todas as dimensões de que são capazes" (Carvalho 2003, p.70).

Segundo a autora, os professores devem refletir sobre suas experiências no trabalho com crianças e continuar a procurar todas as oportunidades adequadas e possíveis para a promoção da aprendizagem delas.

\section{Aprendizagem construtivista de Ciências na educação infantil}

Pesquisadores em Educação (MOREIRA, 2011; MINTZES, WANDERSEE; NOVAK, 2000; NOVAK; GOWIN, 1999) defendem que por meio de sua participação ativa, o aluno pode construir e reconstruir seu conhecimento, alcançando uma aprendizagem significativa. Neste contexto, é importante que o ensino de Ciências, já nos primeiros anos da Educação Básica, seja concebido com vistas a que o aluno seja protagonista de sua aprendizagem, levando-se em conta os conhecimentos que já possui.

O protagonismo da criança se mostra presente na educação infantil, quando é dada a devida importância à construção do conhecimento por ela, levando-se em conta o conhecimento de mundo e das coisas, que a criança já possui, portanto:

É importante que o entendimento do caráter lúdico não se restrinja apenas às situações de jogos e brincadeiras, mas que seja entendido também nos princípios do prazer e da liberdade, sobretudo a liberdade de possuir o próprio filtro de entendimento e de expressar elaborações, sentimentos, percepções, representações, enfim de se permitir à criança o colocar-se enquanto um explorador contumaz do mundo para devorá-lo, entendê-lo e dele fazer parte de maneira intensamente participativa e significante (ANGOTTI, 2006, p.21).

Oliveira-Formosinho (2007) afirma que a pedagogia construtivista na infância se baseia em pressupostos de que as crianças de zero a seis anos são capazes de adquirir o conhecimento por si só e que o professor deve ser aquele responsável pelo suporte, ou seja, ser o mediador na construção do conhecimento, quando a criança lhe solicitar. Ainda, segundo a autora, a "Pedagogia da Infância" deve estar baseada em uma docência participativa que busque enquanto processo interativo de diálogo, o entendimento das mais complexas relações do indivíduo em sociedade, explicando muitas vezes as necessidades de confronto, na ânsia de construção de um novo conhecimento.

Em um grande rol de possibilidades de construção do conhecimento a serem implementadas no processo educativo, cabe ao professor oferecer as mais diversas abordagens didáticas para o aprendizado da criança. Suas intervenções tornam-se essenciais, tendo como um dos maiores desafios a contextualização social e pedagógica, a construção do conhecimento pela criança dentro da realidade em que vive, valorizando sua participação em todo o processo.

Angotti (2006) destaca a necessidade de se valorizar o conhecimento cotidiano, espontâneo das crianças, afirmando que na educação infantil ocorrem diversas formas de expressão das percepções realizadas pelos órgãos dos sentidos, 
O conhecimento não está estampado apenas nas letras, nas repetições, nas reproduções de atividades sem sentido, nas atividades de caligrafia, na apreensão do código gráfico que permite escrever e ler, ou nas atividades de tapa buraco ou de utilização de tempo para não se objetivar nada de maneira intencionalmente educativa. $\mathrm{O}$ conhecimento na criança se faz inicialmente pela captação de dados, conteúdos, indícios propiciados pelos órgãos dos sentidos que sentem, percebem e possuem condições de elaboração e expressão por meio de diferentes linguagens (ANGOTTI, 2006, p.22).

É relevante, também, mencionarmos que nesse enfoque, a criança é entendida não só como produto de uma dada cultura, mas também enquanto produtora da mesma. Segundo Angotti (2006), ela poderá ser orientada no sentido de ser capaz de se comprometer com a preservação cultural, sendo consciente das possíveis inovações culturais da sociedade na qual está inserida. A proposta da abordagem sociocultural construtivista sobre o desenvolvimento da criança procura, assim, destacar a singularidade do sujeito humano e, ao mesmo tempo, o fato de que este sujeito está indissociavelmente relacionado às demais pessoas e aos referenciais simbólicos presentes nos contextos culturais dos quais participa (MORAES, 1993).

Ainda na perspectiva de aquisição de conhecimento, cabe à Pedagogia articular o conhecimento prévio das crianças e as experiências práticas para a construção de um novo conhecimento. Na perspectiva construtivista, existe a necessidade de que as atividades práticas possam ser planejadas já para a educação infantil, levando-se em conta o conhecimento prévio da criança. Desse modo, a discussão e o diálogo assumem um papel importante e as atividades práticas podem combinar ação e reflexão.

Barberá e Valdés (1996) afirmam que o uso de atividades práticas no ensino de ciências pode proporcionar ao aluno uma experiência direta sobre os fenômenos, permitir contrastar a abstração científica com a realidade e desenvolver o raciocínio prático, bem como, promover um desenvolvimento cognitivo durante a sua execução.

Ao se abordar as atividades práticas como investigação científica, Gil-Pérez e Valdés (1996) destacam que problemas a serem apresentados aos alunos devem ser adequados ao nível de desenvolvimento mental deles, de modo que possam se envolver individualmente ou em grupos. Segundo Rosito (2008), na visão empirista-indutivista, as atividades práticas procuram derivar generalizações indo do particular ao geral, e nessa concepção, a observação é a fonte do conhecimento, pois se acredita que o conhecimento científico é obtido do que se observa, aplicando regras do método científico.

Com a realização de uma atividade experimental pode-se contribuir para o desenvolvimento cognitivo das crianças e torná-las mais ativas, bem como, propiciar que sejam protagonistas de seu aprendizado. Ao se considerar os conhecimentos prévios das crianças se possibilita uma iniciação ao conhecimento científico, privilegiando o desenvolvimento de habilidades por meio da ação direta com o objeto de estudo.

\section{CONSIDERAÇÕES FINAIS}

As concepções e orientações descritas nesse trabalho ressaltam que o ensino de ciências na educação infantil, pode representar momentos muito significativos para as 
crianças, principalmente quando elas têm uma participação ativa, despertando o interesse para a aprendizagem do conteúdo específico e contribuindo para desenvolvimento cognitivo. Atividades diversificadas realizadas no ensino de ciências na educação infantil podem proporcionar prazer e envolvimento dos estudantes, pode conduzir à ressignificação dos conhecimentos prévios e propiciar a apreensão de conceitos científicos.

No texto é destacada a necessidade de que haja uma postura metodológica no ensino de ciências que possibilite e contribua para a criação de momentos nos quais as crianças possam ampliar sua curiosidade e seu interesse na exploração de diversos materiais e ambientes, analisando e diferenciando seus atributos. Desta forma, a ação da criança sobre o meio físico e social, oportuniza a construção de um conhecimento novo, bem como a assimilação de regras e valores em situações interativas, desenvolvendo seu senso crítico.

O protagonismo na infância é destacado na ótica construtivista de articulação da aquisição do conhecimento científico com o conhecimento que as crianças trazem do meio social e cultural em que vivem. As atividades práticas são defendidas como de grande importância, caracterizadas como instrumento capaz de fomentar a discussão e o diálogo, assumindo um papel de fator motivacional que combina a ação e a reflexão. Nesse enfoque, o professor tem um papel fundamental nas atividades do ensino de ciências, pois necessita ter uma atitude de socialização com as crianças, incentivando-as e fazendo perguntas para promover o pensamento crítico e a expansão da aprendizagem.

A ideia de que as crianças por meio de suas inquietações e interpretações de elementos do mundo que as cerca, podem refletir sobre explicações historicamente elaboradas sobre fenômenos naturais e de fatos sociais, é defendida. As experiências adquiridas por meio da interação com diversas abordagens do ensino de ciências contribuem para que as crianças desenvolvam habilidades que as levem a valorizar a ações investigativas.

Concepções apresentadas indicam que uma maior variedade de atividades aplicadas no ensino de ciências na educação infantil, pode contribuir para aspectos que vão muito além das questões específicas do saber científico, podendo atingir objetivos vinculados à dimensão afetiva, respeito às opiniões divergentes e valorização do trabalho em grupo. A grande relevância do ensino de ciências na educação infantil pode ser definida pela dinamicidade que imprime às aulas, tanto nas intervenções teóricas como nas práticas, possibilitando ao aluno ampliar seus conhecimentos sobre os fenômenos estudados, permitindo-lhe uma melhor compreensão da realidade que o cerca.

\section{REFERÊNCIAS}

ANGOTTI, M. Educação Infantil: para que, para quem e por quê. In: ANGOTTI, M. (Org.) Educação Infantil: para que, para quem e por quê? Campinas: Editora Alínea, pp. 15-32, 2006.

BARBERÁ, O.; VALDÉS, P. El trabajo prático em la Enseñanza de Las Ciencias: Una Revisión. Enseñanza de las Ciencias, n. 14, v. 3, pp. 365-379, 1996.

BIZZO, N. M. V. Ciências: fácil ou difícil? São Paulo: Ática, 2002. 
BRASIL. Secretaria da Educação Fundamental. Referencial Curricular Nacional para a Educação Infantil. Conhecimento de Mundo, v. 3. Ministério da Educação e do Desporto. Brasília: MEC/SEF, 1998.

BRUNER, J. The Process of Education. Cambridge, MA: Harvard University Press, 1960.

CARVALHO, A. M. P. Profesores y formadores de profesores colaboran em investigaciones sobre la enseñanza de ciencias. Enseñaza de las Ciências, n. 21, v. 2, pp. 191-197, 2003.

CHALUFOUR, I.; WORTH, K. Discovering Nature With Young Children. St. Paul, MN: Redleaf Press, 2003.

CROFT, D. J. An activities handbook for teachers of young children. Boston: Houghton Mifflin Company, 2000.

EDIGER, M. Philosophy of kindergarten education. CUHK Education Journal, n. 17, v. 1, pp. 89-94, 1989.

ELIASON, C.; JENKINS, L. A practical guide to early childhood curriculum. Upper Saddle River, NJ: Prentice Hall, 2003.

GIL PÉREZ, D.; VALDÉS, C. P. La orientacion de las prácticas de laboratorio como investigación: un ejemplo ilustrativo. Enseñanza de las Ciencias, n. 14, v. 2, pp. 155-163, 1996.

HILL, L. T.; STREMMEL, A. J.; FU, V. R. Teaching as inquiry: Rethink curriculum in early childhood education. Boston, MA: Pearson Education, 2005.

HOWE, A. C. Science in early chidhood education. In: SPODEK B. (Org.), Handbook of Research on the Education of Young Children. New York: Macmilan, pp. 225-235, 1993.

JENESS, M. Schoolyard hikes. Science and Children, n. 24, v. 6, pp. 23-35, 1987.

KITCHER, P. The Child as Parent of the Scientist. Mind and Language, n. 3, v. 3, pp. 217-228, 1988.

LIND, K. K. Exploring science in early childhood education. Albany, NY: Delmar, 2000.

LURIA, A. R. Linguagem e desenvolvimento intelectual na criança. Porto Alegre: Artes Médicas, 1985.

MINTZES, J.; WANDERSEE, J.; NOVAK, J. Ensinando Ciência para a compreensão. Lisboa: Plátano Edições Técnicas, 2000.

MORAES, A. C. R. Meio ambiente e ciências humanas. São Paulo: HUCITEC, 1993.

MOREIRA, M. A. Aprendizagem Significativa. São Paulo: Editora e Livraria da Física, 2011.

NOVAK, J.; GOWIN, D. B. Aprender a Aprender. 2. ed. Lisboa: Plátano Edições Técnicas, 1999.

OLIVEIRA-FORMOSINHO, J. Pedagogia da infância: reconstruindo uma práxis de participação. In: OLIVEIRA-FORMOSINHO, J.; KISHIMOTO, T. M.; PINAZZA, M. A. Pedagogia da Infância: dialogando com o passado e reconstruindo o futuro. Porto Alegre: Artmed, pp. 13-36, 2007.

PIAGET, J.; INHELDER, B. The Psychology of the Child. New York, NY: Basic Books, 2000 . 
RILEY, D. A.; ROACH, M. A. Helping teachers grow: Toward theory and practice of an "emerging curriculum" of staff development. Early Childhood Educational Journal, n. 33, v. 5, pp. 363-370, 2006.

ROSA, R. T. D. Ensino de Ciências na Educação Infantil. In: CRAIDY, C.; KAERCHER, G. E. (Org.). Educação Infantil: Pra que te quero? Porto Alegre: Mediação, 2007.

ROSITO, B. A. O ensino de Ciências e a experimentação. Em: MORAES, R. (Org.). Construtivismo e ensino de Ciências: reflexões epistemológicas e metodológicas. Porto Alegre: Edipucrs, pp. 13 - 35, 2008.

SCRIPTORI, C. C. A matemática na Educação Infantil: uma visão psicogenética. In: GUIMARÃES, C. M. (Org.). Perspectivas para Educação Infantil. Araraquara: Junqueira e Marin, pp. 125-156, 2005.

SPODEK, B.; SARACHO, O. Ensinando crianças de três a oito anos. Porto Alegre: Artmed, 1998.

TU, T.; HSIAO, W. Preschool teacher-child verbal interactions in Science teaching. Electronic Journal of Science Education, n. 12, v. 3, pp. 1-23, 2008.

TRUNDLE, K. C.; SACKES; M. Sky observations by the book: Lessons for teaching young children astronomy concepts with picture books. Science and Children, n. 46, v. 1, pp. 36-39, 2008.

VYGOTSKY, L. S. Pensamento e Linguagem. 3. ed. São Paulo: Martins Fontes, 2005.

WORTH, K.; GROLLMAN, S. Worms, Shadows, and Whirlpools: Science in the early Childhood Classroom. St. Paul, MN: Redleaf Press, 2003.

Recebido em:08 de março/2018

Aprovado em: 14 de julho/2018 